\title{
Prevalence, serodiversity and antibiogram of enterotoxigenic Escherichia coli (ETEC) in diarrhoeic calves and lambs of Kashmir valley (J\&K), India
}

\author{
Rusheeba Manzoor ${ }^{1}$, Mohammad Irfan Shah², Asma-ul-husna ${ }^{1}$, Shakil Ahmad Wani', \\ Farhat Pandit ${ }^{1}$, Pervaiz Ahmad Dar ${ }^{1}$, Mohammad Iqbal Mir ${ }^{3}$
}

${ }^{1}$ Division of Veterinary Microbiology and Immunology, Faculty of Veterinary Sciences and Animal Husbandry Sher-e-Kashmir University of Agricultural Sciences \& Technology, Kashmir Shuhama Campus, Srinagar- 190006, INDIA

${ }^{2}$ Division of Veterinary Pharmacology and Toxicology, IVRI, Izatnagar, Bareilly 243122, Uttar Pradesh

${ }^{3}$ Division of Fish Pathology, Faculty of Fisheries Sher-e-Kashmir University of Agricultural Sciences \& Technology, Kashmir, Rangil, Ganderbal 190006

*Corresponding author. E-mail: qadrijavid2008@gmail.com

Received: November 24, 2014; Revised received: May 26, 2015; Accepted: June 12, 2015

\begin{abstract}
Enterotoxigenic E. coli (ETEC) is the major cause of diarrhoea in neonatal animals. This study determined the prevalence, serological diversity, virulence gene profile and in-vitro antibiogram of ETEC isolates from diarrhoeic faeces of calves and lambs. The prevalence rate of ETEC in lambs was recorded $18.46 \%$ with 08 as predominant serotype. However, in calves the prevalence rate was recorded $8.57 \%$ with 015 and 026 as predominant serotypes. The antibiogram screening showed differential susceptibility pattern among ETEC isolates with highest resistance to ampicillin and highest sensitivity to enrofloxacin. In the present study, for the first time it was reported that the diarrhoea in calves and lambs occur due to virulent gene est not due to elt gene, which was absent in all the isolates.
\end{abstract}

Keywords: Calves, Diarrhoea, Lambs, PCR

\section{INTRODUCTION}

Neonatal diarrhoea during first few weeks of life is a leading cause of economic losses to the livestock industry all over the world. There are six different groups of Escherichia coli associated with neonatal diarrhoea in humans and animals including entero-pathogenic E. coli (EPEC), entero-aggregative E. coli (EAEC), entero toxigenic E. coli (ETEC), entero-invasive E. coli (EIEC), diffusely-adherent $E$. coli (DAEC) and shiga-toxin producing E. coli (STEC) (Coxen et al., 2013). ETEC is the most common group associated with the neonatal dia rhoea in animals causing significant morbidity and mortality (Kolanda et al., 2015).

Like other $E$. coli strains, ETEC is serotyped based on the combination of $173 \mathrm{O}$ (somatic) antigens, $80 \mathrm{H}$ (flagellar) antigens and $56 \mathrm{~K}$ (capsular) antigens (Orskov and Orskov, 1992). Detection of enterotoxins by ELISA or their corresponding genes by PCR are extensively used to identify ETEC. ETEC mainly produce two enterotoxins namely heat stable (ST) and heat labile (LT), which are encoded by est and elt genes, respectively. These enter toxins may be cytotoxic which damage mucosal cells or cytotonic which induce secretion of water and electrolytes (Philip et al., 2010).

The present study was undertaken with the objectives to determine the prevalence and serodiversity of ETEC in diarrhoeic calves and lambs, to study the distribution of virulence genes (est and elt) and to determine the in-vitro antibiogram of ETEC isolates.

\section{MATERIALS AND METHODS}

Sampling and isolation of $\boldsymbol{E}$. coli isolates: A total of 200 faecal samples from diarrhoeic calves and lambs upto 16 weeks of age were collected from organized livestock farms and individual livestock owners of Kashmir Valley. The samples were collected by rectal swabbing and transferred to laboratory on ice.

Faecal samples were immediately inoculated on MacConkey's agar (Hi-Media, Mumbai, India) plates. After overnight incubation at $37^{\circ} \mathrm{C}$, two to three rose pink colonies per plate were randomly picked up and subcultured onto Eosin methylene blue (EMB) agar plates to observe the characteristic metallic sheen of $E$. coli. Well separated colonies were picked up on nutrient agar slants as pure culture and subjected to standard morphological and biochemical tests as described by Buchanan and Gibbon (1994).

Extraction of bacterial DNA: $E$. coli isolates were grown in nutrient broth (Hi- Media) at $37^{\circ} \mathrm{C}$ overnight. Organisms from $1.5 \mathrm{ml}$ growth were pelleted by centrifugation at $10,000 \mathrm{rpm}$ for $10 \mathrm{~min}$. The bacterial 
pellet was re-suspended in $150 \mu$ l of sterile distilled water. The bacteria were lysed by boiling for $10 \mathrm{~min}$ in a water bath. The lysate was centrifuged and the supernatant was used directly as template for PCR.

Detection of virulence genes by PCR: $E$. coli isolates were subjected to PCR for detection of elt and est genes. PCR was performed on Gene Amp PCR System 2400 thermal cycler (Applied Biosystems, USA). The primers and the predicted length of PCR amplification products are listed in Table 1.

PCR reactions were carried out in a $25 \mu$ l volume as per the method of Itoh et al. (1992). Each reaction consisted of $2.0 \mu \mathrm{l}$ of template DNA, $2.5 \mu \mathrm{l}$ of $10 \mathrm{X}$ PCR buffer, $0.2 \mu \mathrm{l}$ of $100 \mathrm{mM}$ dNTP mix, $20 \mathrm{pmol}$ of $0.5 \mu \mathrm{l}$ of forward primer and reverse primer, $2.0 \mu \mathrm{l}$ of $25 \mathrm{mM} \mathrm{MgCl}_{2}, 0.2 \mu$ l of Taq DNA polymerase (1 Unit) and $17.1 \mu \mathrm{l}$ of Nuclease Free Water (NFW). The PCR was carried for 25 cycles comprising of $2 \mathrm{~min}$ of initial denaturation at $94^{\circ} \mathrm{C}$ followed by denaturation of 30 sec at $94^{\circ} \mathrm{C}$, annealing of $1 \mathrm{~min}$ at $47^{\circ} \mathrm{C}$, extension of $1.5 \mathrm{~min}$ at $72^{\circ} \mathrm{C}$ and final extension of $5 \mathrm{~min}$ at $72^{\circ} \mathrm{C}$. Amplified PCR products were analyzed by electrophoresis in $2 \%(\mathrm{w} / \mathrm{v})$ agarose gel containing ethidium bromide $(0.5 \mu \mathrm{g} / \mathrm{ml})$ (Sambrook and Russel, 2001).The products were visualized under UV illumination and documented with Gel Doc System (Ultracam Digital Imaging, Ultra Lum. Inc, Claremont, CA).

Serogrouping: The E. coli isolates were serogrouped on the basis of their $\mathrm{O}$ antigen by National Salmonella and Escherichia Centre, Central Research Institute, Kasauli, H.P. 173204(India).

Antibiotic sensitivity test: In-vitro antibiotic sensitivity pattern of the ETEC isolates to various antimicrobial agents was determined by standard disc diffusion method on Mueller-Hinton agar. The antibiotics used in the test included sulphadiazine $(300 \mathrm{mcg})$, chloramphenicol (30 mcg), gentamicin (10 mcg), nalidixic acid (30 mcg), amikacin (30 mcg), amoxicillin-clauvalanic acid (10 $\mathrm{mcg}$ ), neomycin (30 mcg), tetracycline (30 mcg), streptomycin (10 mcg), ampicillin (10 mcg), enrofloxacin (10 mcg), ceftrizone $(30 \mathrm{mcg})$, cefoperazone $(75 \mathrm{mcg})$, norfloxacin (10 mcg). The interpretation of the isolates as sensitive, intermediate, and resistant was done as per manufacturer's instructions.

\section{RESULTS}

A total of 200 diarrhoeic faecal samples from calves and lambs were collected (Table 2). Out of 200 E. coli isolates 30 were detected to be ETEC on basis of est amplification. Thus, the overall prevalence of ETEC was recorded as $15 \%$.

Out of $130 \mathrm{E}$. coli isolates from lambs, 24 (18.46\%) isolates carried est virulence gene and were designated as ETEC (Table3). Twenty one of the ETEC isolates belonged to eight different serogroups (Table 4), 2 isolates were rough and the remaining one isolate was untypeable. Serogroup O8 was the most prevalent among the lamb isolates.

Of the $70 \mathrm{E}$. coli isolates from calves, $6(8.57 \%)$ isolates carried $e s t$ virulence gene and were detected as ETEC (Table3). Four ETEC isolates belonged to two different serogroups and one isolate was rough and the remaining one isolate was untypeable (Table 4). Serogroups O15 and $\mathrm{O} 26$ of ETEC were the most prevalent among the calf isolates.

Table 1. Details of primers used in this study.

\begin{tabular}{|c|c|c|c|c|}
\hline $\begin{array}{l}\text { Target } \\
\text { gene }\end{array}$ & Sequence $5^{\prime} \rightarrow 3^{\prime}$ & $\begin{array}{l}\text { Amplicon size } \\
\text { (bp) }\end{array}$ & $\begin{array}{l}\text { Primer } \\
\text { Conc. }\end{array}$ & Reference \\
\hline \multirow{2}{*}{ elt } & AGCAGGTTTCCCACCGGATCACCA & \multirow{2}{*}{132} & $0.5 \mu \mathrm{M}$ & \multirow{2}{*}{$\begin{array}{l}\text { Itoh et } \\
(1992)\end{array}$} \\
\hline & GTGCTCAGATTCTGGGTCTC & & $0.5 \mu \mathrm{M}$ & \\
\hline \multirow{2}{*}{ est } & TTTATTTCTGTATTGTCTTT & \multirow{2}{*}{171} & $1 \mu \mathrm{M}$ & \multirow{2}{*}{$\begin{array}{l}\text { Itoh } \\
(1992)\end{array}$} \\
\hline & ATTACAACACAGTTCACAG & & $1 \mu \mathrm{M}$ & \\
\hline
\end{tabular}

Table 2. Prevalence of ETEC in Kashmir valley.

\begin{tabular}{|c|c|c|c|c|}
\hline \multirow{2}{*}{ Source } & \multirow{2}{*}{ Species } & \multirow{2}{*}{ No. of samples } & \multicolumn{2}{|c|}{ Positive samples for ETEC } \\
\hline & & & No. & $\%$ \\
\hline Sheep Husbandry, Department, Zakura & Ovine & 10 & 3 & 30 \\
\hline Sheep Breeding Farm, Dachigam & Ovine & 15 & 4 & 26.66 \\
\hline $\begin{array}{l}\text { Mountain Research Centre for Sheep and } \\
\text { Goat, Shuhama }\end{array}$ & Ovine & 62 & 9 & 14.5 \\
\hline $\begin{array}{l}\text { Mountain Livestock Research Institute, } \\
\text { Mansbal }\end{array}$ & Bovine & 16 & 1 & 6.25 \\
\hline Military Dairy Farm, Qamarwari & Bovine & 2 & 0 & 0 \\
\hline Private owners & Ovine & 43 & 8 & 18.6 \\
\hline Private owners & Bovine & 52 & 5 & 9.61 \\
\hline Total & & 200 & 30 & 15 \\
\hline
\end{tabular}


Table 3. Virulence gene profile of ETEC in diarrhoeic calves and lambs.

\begin{tabular}{llll}
\hline \multicolumn{1}{c}{ Number of Samples } & $\begin{array}{l}\text { No. of isolates with at } \\
\text { least 1 virulence gene }\end{array}$ & Pathotype & Percentage of isolates \\
\hline Dirarrhoeic lambs (130) & 24 & ETEC & 18.46 \\
Diarrhoeic calves (70) & 6 & ETEC & 8.57 \\
\hline
\end{tabular}

Table 4. Serogroup diversity of Enterotoxigenic E. coli from diarrhoeic calves and lambs.

\begin{tabular}{lcccc}
\hline & & No. of isolates from & Total (30) & Percentage \\
\cline { 2 - 4 } Serogroup & Calves (6) & Lambs (24) & 6 & 20.00 \\
\hline O8 & 0 & 6 & 2 & 6.66 \\
O15 & 2 & 0 & 4 & 13.33 \\
O17 & 0 & 4 & 2 & 6.66 \\
O26 & 2 & 0 & 1 & 3.33 \\
O89 & 0 & 1 & 1 & 3.33 \\
O91 & 0 & 1 & 2 & 6.66 \\
O106 & 0 & 2 & 1 & 3.33 \\
O109 & 0 & 1 & 5 & 16.66 \\
O159 & 0 & 5 & 1 & 3.33 \\
O192 & 0 & 1 & 3 & 10.00 \\
Rough & 1 & 2 & 2 & 6.66 \\
Untypeable & 1 & 1 & 30 & 100.00 \\
\hline Total & 6 & 24 & \\
\hline
\end{tabular}

Altogether, 30 ETEC isolates from both diarrhoeic lambs and calves carried est gene but none of the isolate carried elt gene. The representative gene profile is depicted in Fig. 1.

The 30 ETEC isolated from diarrhoeic calves and lambs were tested against 14 different antimicrobials for their susceptibility (Fig. 2). Most of the ETEC isolates showed resistance to ampicillin $(86.66 \%)$, nalidixic acid $(80 \%)$, cefoperazone $(66.6 \%)$, streptomycin $(66.6$ $\%)$ and tetracycline $(66.6 \%)$ but were sensitive to enrofloxacin (86.66\%), sulphadiazine (83.33\%), norfloxacin $(83.33 \%)$, gentamicin $(66.6 \%)$ and chloramphenicol $(66.6 \%)$.

\section{DISCUSSION}

In present study, the prevalence rate of ETEC was recorded $18.46 \%$ and $8.57 \%$ in diarrhoeic lambs and calves, respectively. Earlier investigation by Myers (1975) in Montana recorded a prevalence rate of $18 \%$ in diarrhoeic calves. A study by Darong et al. (2010) in China reported a prevalence rate of $15.89 \%$ in piglets. However, a study by Sivaswamy and Gyles (1976) reported a prevalence rate of $36 \%$ of ETEC in diarrhoeic calves which is much higher than recorded in our study. This variation in prevalence rate may be associated with different factors such as species, season of the study, geographical location, environment and hygienic conditions in the farm.

In lambs we recorded O8 ETEC as the predominant serogroup as $20 \%$ of the isolates were positive for O8 antigen. This finding is similar to earlier report by Wani et al. (2003), who also recorded O8 as the most dominant serogroup of ETEC in Kashmir Valley with $13.33 \%$ prevalence rate. However, in calf diarrhoea we recorded $\mathrm{O} 15$ and $\mathrm{O} 26$ as dominant serogroup with prevalence rate of $6.6 \%$. They also recorded 015 and O26 as predominant serogroup in diarrhoeic calves of Kashmir Valley with prevalence rate of $3.33 \%$. The predominance of $\mathrm{O} 8$ in diarrhoeic lambs (Blanco et al., 1996 and Wray and Thomlinson, 1991) and O15 and O26 in diarrhoeic calves (Tripathi and Soni, 1984) has been previously reported.

We also studied the ETEC isolates for the presence of virulence genes, est and elt, by PCR method. The est gene was detected in 30 out of $200(15 \%)$ E. coli isolates, whereas the elt was not detected in any of the isolates. This finding is in agreement with the study by Bradford et al. (1999), who were not able to detect elt gene in any $E$. coli isolate from the diarrhoreic calves but detected est gene in 8 out of 32 isolates (25\%). This is more likely because only human and porcine ETEC strains are able to produce LT (Gyles, 1992).

The analysis of antibiotic resistance pattern showed that the ETEC isolates are resistant to ampicillin, 


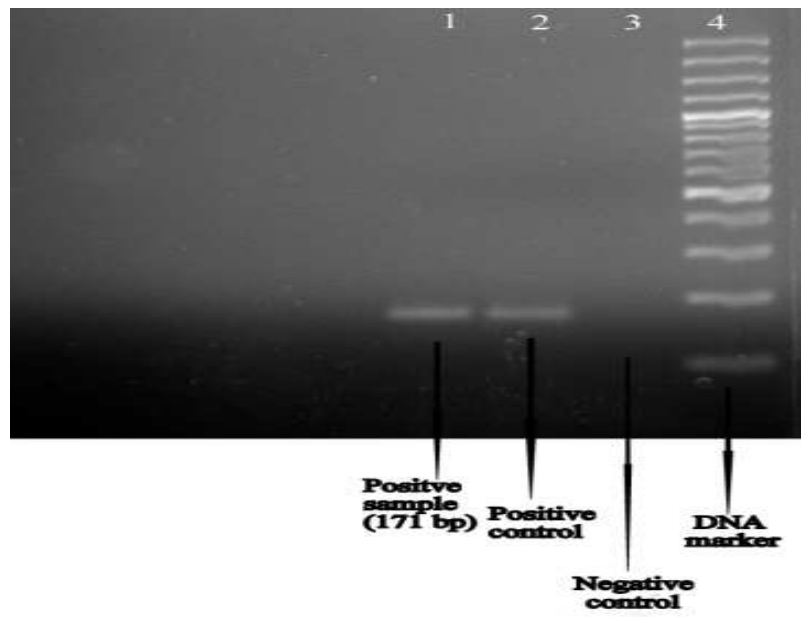

Fig. 1. Representative virulence gene profile of ETEC isolated from diarrhoeic calves and lambs using PCR. Lane 1, est positive. Lane 2, positive control. Lane 3, negative control. Lane 4, 100 bp DNA ladder.

nalidixic acid, cefoperazone, streptomycin and tetracycline, and_sensitive to enrofloxacin, sulphadiazine, norfloxacin, gentamicin and chloramphenicol. These findings are in agreement with findings of Wani et al. (2013) who reported highest percentage of ETEC being resistant to ampicillin and sensitive to chloramphenicol, enrofloxacin, norfloxacin and gentamicin. Earlier, Seh et al. (2000) also reported $90.9 \%$ sensitivity of ETEC isolates to ciprofloxacin and norfloxacin and complete resistance to ampicillin/cloxacillin, erythromycin and cefadroxil. This finding suggests that use of antibiotic for disease prevention and treatment in animals may be responsible for the resistant phenotype in ETEC isolates.

\section{Conclusion}

The prevalence of ETEC in lambs was recorded 18.46 $\%$ with $\mathrm{O} 8$ as predominant serotypes, whereas in calves the prevalence was $8.57 \%$ with $\mathrm{O} 15$ and $\mathrm{O} 26$ as predominant serotypes. The virulence gene est was detected in all ETEC isolates, whereas elt gene was not detected in any of the isolate. Differential susceptibility pattern for antibiotics were observed among ETEC isolates with highest resistance to ampicillin and highest sensitivity to enrofloxacin. The present study leaves scope for similar investigation in human diarrhoeic samples to precisely elucidate the zoonotic significance of ETEC in this part of globe.

\section{REFERENCES}

Blanco, J., Cid, D., Blanco, E., Blanco, M., Ruiz, J., Quiteira, S.and Fuente, R. (1996). Serogroups, toxins and antibiotic resistance of Escherichia coli strains isolated from diarrhoeic lambs in Spain. Veterinary Microbiology, 18 :209-217.

Bradford, P.A., Petersen, P.J., Fingerman, I.M. and White, D.G. (1999). Characterization of expanded

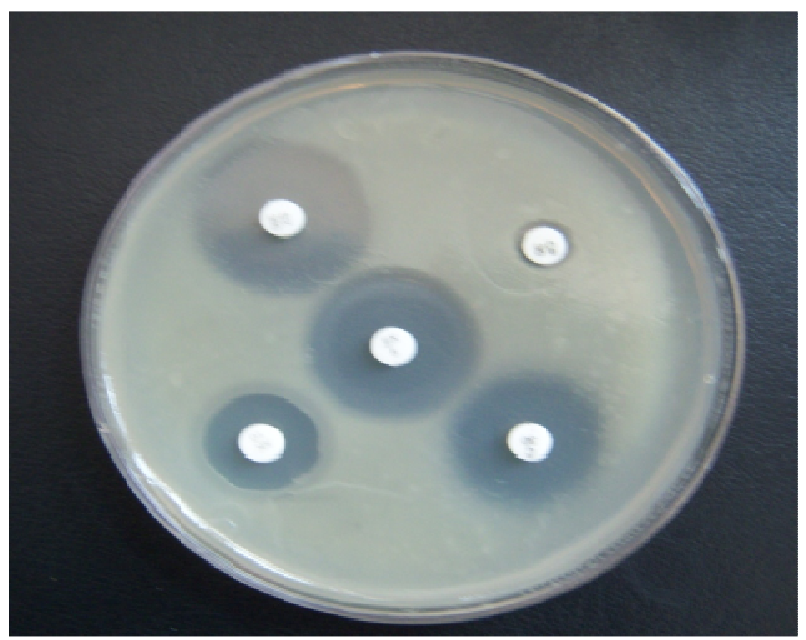

Fig. 2. Representative antimicrobial drug sensitivity pattern of ETEC isolates from diarrhoeic calves and lambs.

-spectrum cephalosporin resistance in $E$. coli isolates associated with bovine calf diarrhoeal disease. $J$. Antimicrobial Chemotherapy, 44:607-610.

Buchanan, R.E. and Gibbon, N.E. (1994). Bergey's Manual of Determinative Bacteriology. $9^{\text {th }}$ edition. Williams and Wilkins, Baltimore, pp787.

Croxen, M.A., Law, R.J., Scholz, R., Keeney, K.M., Wlodarska, M., and Finlay, B.B. (2013). Recent advances in understanding enteric pathogenic Escherichia coli. Clin. Microbiol. Rev., 26: 82-880.

Darong, C., Yuan, Z.S., Lang, C.X., Pan, G.X., Wei, D.W. and Chang, S.H. (2010). Rapid diagnosis of ETEC and HPI-harboring Escherichia coli infection in newborn piglets with diarrhoea. African Journal of Microbiology Research, 4(7)-:575-580.

Gyles, C.L. (1992). Escherichia coli cytotoxins and enterotoxins. Can J Microbiol., 38:734-46.

Itoh, F., Ogino, T., Itoh, F. and Watanabe, H. (1992). Differentiation and detection of pathogenic determinants among diarrhoeagenic Escherichia coli by polymerase chain reaction using mixed primers. Jpn. J. Clin. Med., 50: 343-347.

Kolenda, R., Burdukiewicz, M. and Schierack, P (2015). A systematic review and meta-analysis of the epidemiology of pathogenic Escherichia coli of calves and the role of calves as reservoirs for human pathogenic E. coli. Front. Cell. Infect. Microbiol.5: 23.

Myers, L.L. (1975). Characterization of Escherichia coli obtained from newborn calves with diarrhoea. Infection and Immunity, 11: 493-496.

Orskov, F. and Orskov, I. (1992). Escherichia coli serotyping and disease in man and animals. Can. J.Microbiol., 38: 699-704.

Philipp, R., Weiglmeier,M., Rösch, P and Berkner, H. (2010). Cure and Curse: E. coli Heat-Stable Enterotoxin and Its Receptor Guanylyl Cyclase C. 
Toxins, 2: 2213-2229.

Sambrook, J., Russel, D.W. (2001). Molecular Cloning - A Laboratory Manual. Cold Spring Harbour, New York, USA.

Seh, D.K., Soni, S.S., Kashyap, S.K. and Shringi, B.N. (2000). Seroprevalence, antibiotic sensitivity pattern and transfer of plasmid coded characters of $E$. coli. Indian Vet. J., 81: 6-8.

Sivaswamy, G. and Gyles, C.L. (1976). The prevalence of enterotoxigenic Escherichia coli in the faeces of calves with diarrhoea. Canad. J. Comp. Med., 40: 241-246.

Tripathi, R.D. and Soni, J.L. (1984). Enteropathogenic $E$. coli in neonatal calf diarrhoea in crossbred calves. Indian Vet. J., 61: 4-8.

Wani, S.A., Bhat, M.A., Munshi, Z.H., Qureshi, S. and Buch, A.S. ( 2003). Isolation and in-vitro sensitivity pattern of pathogenic Escherichia coli from diarrhoeic lambs and calves. Journal of Animal Sciences, 73 (2): $168-170$.

Wani, S.A., Hussain, I., Beg, S.A., Rather, M.A., Kabli, Z.A., Mir, M.A. and Nishikawa,

Y.(2013). Diarrhoeagenic Escherichia coli and Salmonellae in calves and lambs in Kashmir. absence, prevalence and antibiogram. Rev. sci. tech. Off. Int. Epiz, pp 32(3).

Wray, C. and Thomlinson, J.R. (1991). Factors influencing occurrence of colibacillosis in calves. Veterinary Record., 96(3): 52-56. 